\title{
Development and Performance Evaluation of a Modified Africa Bush Mango (Irvingia gabomensis) Cracker
}

\author{
${ }^{1}$ BUSARI, RA; ${ }^{2 *}$ AKPENPUUN, TD; ${ }^{2}$ IYANDA, MO \\ ${ }^{I}$ Depertment of Agricultural and Biosystems Engineering, Kwara State University, Malete \\ ${ }^{2}$ Depertment of Agricultural and Biosystems Engineering, University of Ilorin, Ilorin, Nigeria \\ *Corresponding author Email: akpenpuun.td@unilorin.edu.ng
}

\begin{abstract}
An African bush mango cracker was modified and fabricated to address the challenges of the conventional method of cracking nuts which involves striking the nut. The tedious nature of this process constitutes a major setback which restricts the production to a very small scale. The cracker consists of a frame, cracking table, slidercrank mechanism, hopper, feed chute, slot, cracking unit electric motor and reduction gear. The machine was evaluated with respect to throughput capacity and cracking efficiency at five moisture content levels $(13,15,17,20$ and 25\%) moisture content (MC) dry basis. At $13 \% \mathrm{MC}$; the output capacity was $7.13 \mathrm{~kg} / \mathrm{hr}$ and cracking efficiency was $98 \%$ while at $15 \% \mathrm{MC}$; the output capacity and cracking efficiency reduced to $7.04 \mathrm{~kg} / \mathrm{hr}$ and $96 \%$ respectively. Similarly, at $17 \%$ MC; output capacity and cracking efficiency further reduced to $7.02 \mathrm{~kg} / \mathrm{hr}$ and $95 \%$ respectively while at $20 \% \mathrm{MC}$; the output capacity and cracking efficiency were reduced to $6.74 \mathrm{~kg} / \mathrm{hr}$ and $93 \%$ respectively. There was a similar trend when the test was performed at $25 \% \mathrm{MC}$, as the output capacity and cracking efficiency showed a further reduction to $6.50 \mathrm{~kg} / \mathrm{hr}$ and $90 \%$ respectively. These results were different from the old cracker that had throughput capacity and cracking efficiency of $4.32 \mathrm{~kg} / \mathrm{hr}$ and $70 \%$ respectively. A significant trend was established which showed that as the moisture content of the nuts decreases, machine performance increases. Based on these results, drudgery and other hazards associated with manual cracking of the African bush mango are eliminated, the machine saves time and made processing of the seeds easier.
\end{abstract}

\section{DOI: https://dx.doi.org/10.4314/jasem.v23i2.14}

Copyright: Copyright $(02019$ Busari et al. This is an open access article distributed under the Creative Commons Attribution License (CCL), which permits unrestricted use, distribution, and reproduction in any medium, provided the original work is properly cited.

Dates: Received: 10 December 2018; Revised: 21 January 2019; Accepted 27 January 2019

Keywords; Modification, Machine, Mango, Capacity, Efficiency

Irvingia gabomensis is a non-timber forest product, made up of tree trunk (stem), leaves, roots, and fruits. The fruit comprises of a fleshy part and the nut, which consist of a hard shell and the kernel/seed. Its seeds have an outer brown testa (hull) and two white cotyledons. However, two species which are commonly available is the Irvingia gabonesis which is found from Nigeria to Congo, and Irvingia Wombolu which is found along the coastal region of Senegal to Uganda (Ladipo et. al., 1996). Irvingia gabonesis common names are bush mango, African mango, wild mango or dika nut plant. This fruit is like that of a small, cultivated mango in appearance, although they are unrelated. The pulp of this fruit is eaten fresh and the kernel of the nut is a food additive. Cracking of Africa bush mango is a key operation in the processing of nut as it separates the kernel from the dried nut. Traditionally, nuts are cracked manually by striking the nuts in-between stone surfaces. The output and the tedious nature of this process form a major bottleneck, which restricts the production to a very small scale. Furthermore, the manual process often constitutes a source of injury to the operator who often gets hit by the stone used for cracking. Control of kernel damage is difficult and is often based on the ingenuity of the operator. Separation of kernels from the shells is an arduous task, which is made more difficult when the kernels are broken. As a result of this, the quality and quantity of the product have remained low and therefore renders manual cracking ineffective. However, African bush mango nut is irregular in shape and must be carefully positioned to break the nut along its natural seam. The dried kernel-in-shell is brittle and a large percentage is crushed during the process, thereby reducing the market value of the kernels. There is, therefore, need to develop a system of extracting the seeds by developing a mechanical cracker which could drastically reduce drudgery and increase both production and market values. Asoegwu and Maduire (1996) investigated some physical properties and the cracking energy of Irvingia Gabonensis (Ogbono) nuts. The average sphericity, roundness and density were respectively $53.3 \%$, $73.5 \%$ and $1.35 \mathrm{~g} / \mathrm{cm}^{3}$ at $44.8 \%$ moisture content $(\mathrm{db})$. An impinging velocity of $69.54 \mathrm{~m} / \mathrm{s}$ was adequate to sufficiently crack the seed at the determined moisture content while the energy required for the cracking varied from $17.31 \mathrm{~J}$ to $27.52 \mathrm{~J}$. 
Oluwole et. al., (2004) designed, constructed and evaluated the performance of sheanut-cracker. They reported that the moisture content affected the cracking, breakage and winnowing efficiency. Feed rate also had an effect on the performance evaluation of the machine. Three different vane configurations were employed in carrying out the evaluation and it was observed that the radial vane configuration maintained the best cracking performance. Ogunsina et. al., (2008) designed constructed and evaluated the performance of a table mounted device for cracking dika nut. They reported that the failure of nut was along the line of symmetry the machine gave $100 \%$ cracking efficiency with $24 \%$ breakage in cracking sun-dried dika nut at $6.6 \%$ moisture content (w.b). Diabana, (2009) designed, constructed and evaluated the performance of an African Bush Mango (Irvingia gabonesis) cracker. The machine operated on the principle of reciprocating motion of piston and crankshaft of an engine and it was designed for batch operation. The main components of the machine included connecting rod, cylinder bore and a piston, shaft, cracking tray, and frame. The performance test showed that the moisture content did not affect crackability of the seed. At a moisture content of $8 \%$ $\mathrm{db}$, the machine gave output capacity of $6.32 \mathrm{~kg} / \mathrm{hr}$ and $96 \%$ cracking efficiency while at $21 \% \mathrm{db}$, the machine gave output capacity $4.32 \mathrm{~kg} / \mathrm{hr}$ and $94 \%$ cracking efficiency respectively. Yusuf and Suleimon (2000) reported kernel damage of Bambara groundnut, increasing with increasing drum speed. They obtained a maximum shelling efficiently of $95 \%$ at a drum speed of $450 \mathrm{rpm}$. Oluwole et. al., (2004) designed, constructed and evaluated the performance of sheanutcracker. They reported that the moisture content affected the cracking, breakage and winnowing efficiency. Feed rate also had an effect on the performance evaluation of the machine. Three different vane configurations were employed in carrying out the evaluation and it was observed that the radial vane configuration maintained the best cracking performance. Manuwa (1998) determined the force required in cracking some unidentified palm nut variety and reported the variation of the force with nut size, moisture content and shell thickness. The cracking force ranged between 0.2 and $3.7 \mathrm{KN}$, decreasing with moisture content and increasing with increasing shell thickness and nut size. Generally, nutcrackers (for palm nuts, cashew nut, Bambaranuts, shea butter nut) which are adequate for most nuts are not appropriate for bush mango because it was discovered that the nutshell has an appreciable thickness. The shape was elliptical and ductile than other nuts. It was also observed that the nut cracksbest along its natural line of cleavage, which is the main reason why it is impossible to adopt other nutcrackers.

\section{MATERIALS AND METHODS}

The following factors were considered in modifying African bush mango cracker; reduction in time and energy spent in cracking, use locally available material for constructing the cracker, detachable components, using bolts to attach, for easy repair and maintenance, its designed for continuous operation, incorporation of hopper for easy feeding of the nut into the cracking nut. The following modifications were therefore made on the existing African bush mango cracker;

(i) Incorporation of the hopper and slanted feeding chute for easy loading of the nut into the cracker.

(ii) Discharge chute was provided to enhance quick discharge of the seeds into a collector.

(iii) Newly fabricated cracker was designed for continuous cracking.

(iv) The new machine was simple, light in weight and smaller in size compared with the old machine in term of portability.

(v) The modification resulted to reduced cost of production

(vi) The modification resulted to increased output capacity and efficiency

Power Requirements: The seed of the African bush mango was be placed edgewise in between the fixed block and the slider hammer, the seed is stationery to absorb the impact while the hammer is attached to the slider-crank mechanism, moving in reciprocating form. However, there was energy translation in the process that is kinetic energy in the hammer will be absorbed by the seed which possess potential energy as a result of its position. It, therefore, implies that the kinetic energy in the machine was equal to the potential energy absorbed by the seed.

From the equation of kinetic energy

$K . E=\frac{1}{2} m v^{2}$

Where;K.E=Kinetic Energy, J; M= Mass of hammer, $\mathrm{kg}$; $\mathrm{V}=$ Speed of the hammer, $\mathrm{m} / \mathrm{s}$; From the equation of Potential Energy

$P . E=M g h$

Where; P.E =Potential Energy, J; M= Mass of the seed, kg; $\mathrm{g}=$ Acceleration due to gravity, $\mathrm{m} / \mathrm{s} ; \mathrm{h}=$ Distance traveled by the slider, $\mathrm{m}$

However, from principles based on the assumption of energy loss by the machine through hammer which is equal to the energy absorbed by the seed to crack.

P.E $=$ K.E

(3) 


$$
M g h=1 / 2 m v^{2}(3 a)
$$

Assuming the weight of the hammer is equal to the weight required to crack the seed, and making $\mathrm{v}$ the subject of the formula, equation (3) becomes

$$
v=\sqrt{2 g h}
$$

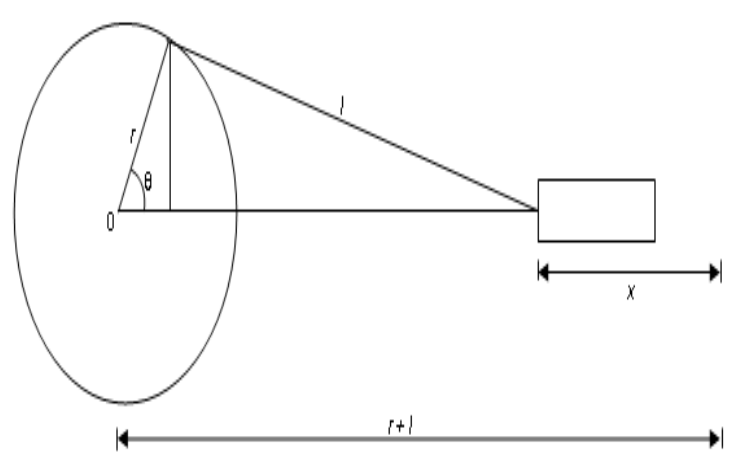

Figure 1: The slider crank mechanism

As the crank connecting the shaft rotates, it moves the slider in linear motion. The distance travel by the slider can, therefore, be determined using the formula as stated in Singh (2005).

$$
X=\frac{r[(1-\cos \theta)+r(1-\cos 2 \theta)]}{4 l}
$$

Where; $r=$ Radius of the crank, $m$; $1=$ Length of the connecting rod, $\mathrm{m} ; \theta=$ Angle between the crank radius and horizontal, $\theta^{0}$

For the design, it is assumed that the crank radius is $150 \mathrm{~mm}$. Length of connecting rod from Singh (2005) is given as

$$
n=l / r
$$

Where; $n=$ constant and value varies from 3.5 to 4 (for internal combustion engines since the mechanism is not an enclosure, the maximum value will be considered).

Therefore, $\mathrm{n}$ is considered to be 4 substituting into equation (6)

$$
4=l / 0.15 ; l=4 * 0.15=0.6=600 \mathrm{~mm}
$$

Where crank angle, $\theta$, is assumed to be $45^{\circ}$. Therefore;

$$
\begin{aligned}
& X=\frac{0.15\left[\left(1-\cos 45^{\circ}\right)+0.15\left(1-\cos 90^{\circ}\right)\right]}{4 * 0.6} \\
& X=\frac{0.044+0.15}{2.4} \\
& X=0.08 m=80 \mathrm{~mm}
\end{aligned}
$$

Substituting the value of $\mathrm{x}$ as $\mathrm{h}$ in equation (4), therefore $\mathrm{v}$ is obtained as;

The speed of the hammer $\mathrm{V}=1.25 \mathrm{~m} / \mathrm{s}$

The velocity at which the slider travel can be equated to the angular speed and its radius

(Khurm, and Gupta 2004).

$V=w r$

Where; V=Speed of the hammer, $\mathrm{m} / \mathrm{s} ; \mathrm{W}=$ Angular velocity, $\mathrm{rad} / \mathrm{s} ; \mathrm{r}=$ Length of connecting $\mathrm{rod}, \mathrm{m}$

$w=v / r$

$\mathrm{V}=1.25 \mathrm{~m} / \mathrm{s}, \quad \mathrm{r}=0.6$

$w=1.25 / 0.6$

$=2.1 \mathrm{rad} / \mathrm{sec}$

As earlier stated by Singh (2005),

$w=2 \pi N / 60$

Where; W=Angular velocity, $\mathrm{rad} / \mathrm{sec} ; \mathrm{N}=$ Number of revolution per minute;

$$
\begin{aligned}
& N=W * 60 / 2 \pi \\
& =2.1 * 60 / 2 \pi(9)
\end{aligned}
$$

Service factor Ks is considered to take care of losses due to transmission. The value of $\mathrm{Ks}$ was obtained from a standard table which is in appendix table B2.

$\mathrm{Ks}=20 \times 1.54=30.8 \mathrm{rpm}$

For the purpose of this design 50 revolutions per minutes is considered.

Power Developed: The power developed by the hammer as a result of the rotation was calculated using the formula given by Singh (2005),

$P=T N / 9550$ 
Where; $\mathrm{P}=$ Power developed, $\mathrm{kw}$; $\mathrm{T}=$ Torque, $\mathrm{N} \mathrm{m}$; $\mathrm{N}=$ Speed of the machine, rpm

But,

$$
T=J G \theta / L
$$

Where; $\mathrm{J}=$ polar moment, $\mathrm{mm}^{4} ; \mathrm{G}=$ Modulus of rigidity, $\mathrm{N} / \mathrm{mm}^{2} ; \Theta=$ Angle of twist, deg; $\mathrm{L}=$ Length of the shaft or connecting rod, $\mathrm{m}$

Polar moment of a solid shaft is given by Singh (2005). $J=\pi d^{4} / 32$

Where;

$$
\begin{aligned}
& d=\pi *(30)^{4} / 32 \\
& =79,521.56 \mathrm{~mm}^{4}
\end{aligned}
$$

$\mathrm{G}=80,000 \mathrm{~N} / \mathrm{mm}^{2}$

$\theta=\pi / 180$

Substituting the above values into equation (11)

$$
\begin{aligned}
& =\frac{80,000 \times 79,521.56 \times \pi}{180 \times 600} \\
& T=185,055.07 \mathrm{~N} . \mathrm{mm}
\end{aligned}
$$

Substituting the obtained torque into equation (10)

$$
\begin{aligned}
& P=\frac{T N}{9550} \\
& =\frac{185,055.07 \times 50}{9550}=968.87 \mathrm{~W}=0.97 \mathrm{~kW}
\end{aligned}
$$

Converting the power obtained to horsepower which is the commonly used rating for an electric motor,

$$
1 H p=746 w
$$

$$
\frac{968.87}{746}=1.3 \mathrm{Hp}
$$

For design purpose, service factor must be considered in other to consider losses in the machine during operation. To obtain the service factor, values were obtained from a standard table which will be appendix table B2.

Therefore to calculate for the maximum power Singh (2005) stated the formula as

$$
K_{S}=\frac{\text { Maximum Rated Power }\left(P_{M}\right)}{\text { Actual Power Re quirement }\left(P_{A}\right)}
$$

Where the actual power requirement is the power calculated which is required to drive the slider

$$
K_{S}=\frac{P_{M}}{1.3} \quad \ldots \text { (13a) }
$$

Form medium shock, worm gear operation and frictional losses for 8hours per day.

$k_{s}=1.54$

$p_{m}=1.5 \times 1.54=2.002=2 \mathrm{Hp}$

The maximum power required is estimated to be 2 Hp $(1.5 \mathrm{Kw})$ and a speed of 50 revolutions per minute. To achieve this speed, an electric motor with a reduction gear is attached to reduce the speed from $1440 \mathrm{rpm}$ to $50 \mathrm{rpm}$.

Description of African Bush Mango Cracker: The cracker consists of the following basic units; frame, hopper, cracking unit, slider hammer, slot, feeding chute, electric motor and reduction gear. Figure2 shows the entire component, the side view, front view and plan elevation of the machine.

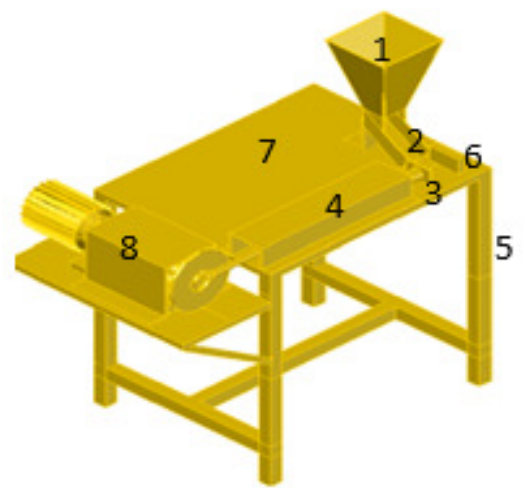

Fig 2: The African bush mango cracker

1 = Hopper $; 2$ = Feeding Chute $; 3$ = Slider Hammer $; 4=$ Slider crank; Mechanism ; 5= Frame; 6. = Fixed Block; 7=Cracking Table; $8=$ Electric Motor

The frame is rectangular shaped $(1050 \times 749 \times 756 \mathrm{~mm})$, designed to house the entire components of the machine and was designed to provide stability and withstand vibration. The hopper was pyramidal with the following dimensions: height $=350 \mathrm{~mm}$, lower hopper opening $=70$ by $70 \mathrm{~mm}$ and upper hopper opening $=200$ by $200 \mathrm{~mm}$. The seeds to be cracked were fed into cracking unit by gravity through feeding chute from the hopper. The cracking unit comprises of fixed block and slider hammer and the unit carried out the function of actually cracking of the seeds, released 
nuts and cracked shells fall into collector through a slot provided.

Mode of Operation: The cracking machine is designed for continuous operation. To achieve this operation, a hopper with slanting feeding chute is incorporated into the machine. The seed flows by gravity from the hopper to the cracking unit. The nut is compressed between the slider and fixed block until it gives with a crack sound that connotes cracking. The cracked seeds fall to the ground or into a container through a slot provided which gives room for another seed to replace it and the process continues.

Machine Evaluation: Performance evaluation was carried out on the cracker to determine the effect of moisture content on output capacity, cracking efficiency and percentage breakage. One hundred nuts were selected for conditioning from the equilibrium moisture content of $13,15,17,20$ and $25 \%$ dry basis by moisture adjustment. But the seeds were first dry to bone dry weight before the addition of water. The amount of water to be added for each batch of the sample was determined from the following relation (Adebona, et.al., 1986)

$W_{W}=W_{S}\left(\frac{M_{2}-M_{1}}{1-M_{2}}\right)$

Where; $W_{W}=$ amount of water to be added, $\mathrm{g} ; W_{S}=$ weight of sample for which moisture is to be adjusted, g; $M_{1 \text { The }}=$ initial moisture content of sample, $\%$; $M_{2 \text { The }}=$ final moisture content of the sample. $\%$

The conditioned samples were weighed before being fed into the cracker. The time spent to crack the weighed sample was taken and recorded. After cracking operation, the cracked wholesome seeds, split seeds, broken nuts, and uncracked seeds were collected, separated and weighed. The following were used for analysis of the results and there were five replications.

$$
\text { Output Capacity }(\mathrm{OC})=\frac{W_{C}}{t} \cdots
$$

Where; $\mathrm{W}_{\mathrm{C}}=$ weight of cracked seeds, $\mathrm{kg}, \mathrm{t}=$ time taken, hr.

Cracking Efficiency $(\mathrm{CE})=\frac{N_{C}}{N_{T}} \times 100$

Where; Nc $=$ Number of cracked kernels, $\mathrm{N}_{\mathrm{T}}=$ Total number of nuts.

Percentage Breakage $(\mathrm{PB})=\frac{N_{b}}{N_{T}} \times 100$

Where; $\mathrm{N}_{\mathrm{b}}=$ Number of broken or partially damaged nuts, $\mathrm{N}_{\mathrm{T}}=$ Total number of seeds.

The statistical analysis was carried out using ANOVA to test for the significant differences in the output capacity at five different moisture content and when the null hypothesis was rejected that there are significant differences in the output capacity. The results of the statistical analysis are presented in Table 2.

\section{RESULTS AND DISCUSSION}

The machine designed and fabricated was tested. The results of the performance evaluation are presented in Table 1.The effect of moisture contents on the output capacity and cracking efficiency is shown in Table 1. The lower the moisture content, the higher the output capacity and the efficiency. Therefore, to have high efficiency, the moisture content must be low. At 13\% $\mathrm{MC}$; the output capacity was $7.13 \mathrm{~kg} / \mathrm{hr}$ and cracking efficiency was $98 \%$ while at $15 \% \mathrm{MC}$; the output capacity and cracking efficiency reduced to $7.04 \mathrm{~kg} / \mathrm{hr}$ and $96 \%$ respectively. Similarly, at $17 \%$ MC; output capacity and cracking efficiency further reduced to $7.02 \mathrm{~kg} / \mathrm{hr}$ and $95 \%$ respectively while at $20 \% \mathrm{MC}$; the output capacity and cracking efficiency came down to $6.74 \mathrm{~kg} / \mathrm{hr}$ and $93 \%$. There was a similar trend when the test was performed at $25 \% \mathrm{MC}$ as the output capacity and cracking efficiency showed a further reduction to $6.50 \mathrm{~kg} / \mathrm{hr}$ and $90 \%$ respectively. These results show a clear difference from old cracker that gave throughput and efficiency of $4.32 \mathrm{~kg} / \mathrm{hr}$ and $70 \%$ respectively.

Table 1: The Results of the performance evaluation of the machine

\begin{tabular}{|c|c|c|c|c|c|}
\hline Parameters & $\begin{array}{l}\text { M C 13\% } \\
\text { db }\end{array}$ & $\begin{array}{l}M \quad C \\
15 \% \text { db }\end{array}$ & $\begin{array}{l}\text { M C } 17 \% \\
\text { db }\end{array}$ & $\begin{array}{l}\text { M C C } \\
\mathbf{2 0 \%} \text { db }\end{array}$ & $\begin{array}{l}\text { M C C } \\
25 \% \text { db }\end{array}$ \\
\hline Weight (kg) & 1.061 & 1.274 & 1.382 & 1.435 & 1.565 \\
\hline Time (hrs) & 0.150 & 0.182 & 0.197 & 0.213 & 0.241 \\
\hline Throughput (kg/hr) & 7.13 & 7.04 & 7.02 & 6.74 & 6.50 \\
\hline Wholesome seeds & 6 & 8 & 12 & 13 & 15 \\
\hline Split seeds & 88 & 85 & 81 & 79 & 75 \\
\hline Broken seeds & 4 & 3 & 2 & 1 & 0 \\
\hline Uncracked seeds & 2 & 4 & 5 & 7 & 10 \\
\hline Efficiency $(\%)$ & 98 & 96 & 95 & 93 & 90 \\
\hline
\end{tabular}


Table 2: Analysis of variance for output capacity of the machine at five different moisture contents

\begin{tabular}{llllll}
\hline Variation & $\begin{array}{l}\text { Degree } \\
\text { of } \\
\text { Freedom }\end{array}$ & $\begin{array}{l}\text { Sum } \\
\text { of } \\
\text { Square }\end{array}$ & $\begin{array}{l}\text { Square } \\
\text { Mean }\end{array}$ & $\mathbf{F}_{\text {cal }}$ & $\mathbf{F}_{\text {tabs }}$ \\
\hline Between Treatment & 4 & 1.36 & 0.3400 & 4.4 & 2.87 \\
Within Treatment & 20 & 1.53 & 0.0765 & & \\
Total & 24 & 2.89 & & & \\
\hline
\end{tabular}

Cost of Productions: The material used and their cost as at the time of fabrication of the Africa bush mango cracker is presented in Table 2 . The cost of production was determined by multiplying the unit cost of each material used by the quantity required. The total sum of all the material cost was taken as the cost of production.

Table: 3 Cost analysis of the construction of Africa bush mango cracking machine

\begin{tabular}{llll}
\hline Materials & Quantity & Unitcost $(\mathrm{N})$ & Cost $(\mathrm{N})$ \\
\hline Square pipe $(4$ by $4 \mathrm{~cm})$ & 2 & 7000 & 14,000 \\
Square pipe $(2.5$ by $2.5 \mathrm{~cm})$ & $1 / 2$ & - & 3,500 \\
Mild-steel plate $(1.5 \mathrm{~mm})$ & $1 / 2$ & & 2,000 \\
Electrode & $1 \mathrm{pkt}$ & - & 1,500 \\
Electric motor & 1 & - & 10,000 \\
Bearing (pillow) & 2 & 750 & 1,500 \\
Bolts and Nut & 20 & 40 & 800 \\
Rod (30mm) & $1 / 2$ length & - & 800 \\
Rod $(20 \mathrm{~mm})$ & $1 / 4$ length & - & 400 \\
Flywheel & 1 & - & 1,000 \\
Painting & - & - & 2,000 \\
Workmanship & - & - & 15,000 \\
Total & - & - & $52,500(\$ 350)$ \\
\hline
\end{tabular}

Conclusion: The proprietary machine is simple in design, low fabrication cost, safe and easy to operate. The principle of operation was by compressing the nut between two solid blocks. A high cracking efficiency was achieved with minimal breakages recorded. The machine saved time, eliminated drudgery and other health hazards associated with manual cracking

\section{REFERENCES}

Asoegwu SN; Maduire, JO (1996). Some Physical Properties and Cracking Energy of Irvingia Gabonensis. J. Nig. Inst. Agric. Engineer. 130139.

Diabana, PD (2009). Design, Construction and Performance Evaluation of an African Bush Mango (Irvingia Gabonesis) Cracking Machine. Unpublished M. Sc Project Submitted to the Department of Agricultural and Environment Engineering, University of Ibadan.

Ladipo DO; Fondown, JM; Ganga, N; Leakey, RRB; Temu, AB; Melnyk M; Vantomme P (1996). Domestication of the Bush Mango (Irvingiaspp): Some Exploitable Intra-specific Variations in West and Central Africa. In Domestication and Commercialization of Non-timber Forest Products in Agro Foresting Systems. Proceedings of an International Conference Held in Nairobi Kenya, 19-23. February Non wood Forest Products 9: 193-205.
Manuwa, SI (1998). Fracture Resistance of Palm Nut to Compressive Loading. Paper Presented at the 20th Annual Conference of the Nigeria Society of Agricultural Institution of Agricultural Engineers at Lagos Airport Hotel, Lagos, Nigeria 9-12th September 1998.

Ogunsina, BS; Bamgboye. AI (2007). Effects of preshelling treatment on the physical properties of cashew nut (Anacardium occidentale). International Agrophysics, 21(4):385-389.

Ogunsina BS; Koya, OA; Adeosun, OO (2008). A Table Mounted Device for Cracking Dika Nut. J. Agric. Engineer. Inter.: 08011: 1

Oluwole FA; Aviara, NA; Haque, MA (2004). Development and Performance Test of a Sheanut Cracker. J. Food Engineer. (65) 117-123.

Singh S (2005). Machine Design Khanna Publishers Delhi Pp 557-704.

Yusuf, DD; Suleiman, ML (2000). Design Development and Performance Evaluation of Bambara Groundnut Shelter. NBTE J Agric. Technol. 8 (1): 43-48. 